\title{
PRESENTACIÓN SIMULTÁNEA DE PÉNFIGOS VULGAR Y FOLIÁCEO
}

\author{
Claudia Marcela Arenasi', María Catalina Cuéllar ${ }^{2}$ \\ ${ }^{1}$ Dermatóloga, Centro Dermatológico Federico Lleras Acosta E.S.E., Docente de Pregrado y Postgrado, \\ Facultad de Medicina. Universidad Militar Nueva Granada, Bogotá, D.C., Colombia \\ ${ }^{2}$ Residente de Dermatología Universidad CES, Centro Dermatológico Federico Lleras Acosta, E.S.E., \\ Bogotá, D.C., Colombia \\ Correspondencia:maria.cata.c@gmail.com
}

Recibido: Mayo 21 de 2014 Aceptado: Septiembre 16 de 2014

\begin{abstract}
Resumen
El pénfigo foliáceo y el pénfigo vulgar son enfermedades autoinmunes caracterizadas por vesículas y ampollas que se rompen fácilmente dejando erosiones superficiales. Las ampollas están localizadas en diferentes sitios de la epidermis dependiendo del perfil inmunológico con el que cursen. Se reporta el caso de una paciente con presentación simultánea de pénfigo vulgar y pénfigo foliáceo, una asociación de baja incidencia con pocos casos informados en la literatura.

Palabras clave: Pénfigo foliáceo, pénfigo vulgar, acantolisis, ampolla
\end{abstract}

\section{SIMULTANEOUS PRESENTATION OF PEMPHIGUS VULGARIS AND FOLIACEUS}

\begin{abstract}
Pemphigus foliaceus and vulgaris are autoimmune diseases characterized by blisters that break easily leaving behind superficial erosions, with different locations in the epidermis depending on the immunologic profile with which they present. We report the case of a patient with simultaneous presentation of pemphigus vulgaris and pemphigus foliaceus, an association of low incidence with few cases reported in the literature.
\end{abstract}

Key words: Pemphigus vulgaris, pemphigus foliaceus, acantholysis, blister

\section{APRESENTAÇÃO SIMULTÂNEA DE PÊNFIGO VULGAR E FOLIÁCEO}

\begin{abstract}
Resumo
O pênfigo foliáceo e o pênfigo vulgar são doenças autoimunes caracterizadas por vesicular e bolhas que se quebram facilmente deixando erosões superficiais. As bolhas ficam localizadas em diferentes regiões da epidermes dependendo do perfil imunológico. Reportamos o caso de um paciente com apresentação simultânea de pênfigo vulgar e pênfigo foliáceo, uma associação de baixa incidência com poucos casos informados na literatura.
\end{abstract}

Palavras-chave: Pênfigo Foliáceo, Pênfigo Vulgar, Acantólises, Bolha 


\section{Introducción}

Los pénfigos son enfermedades ampollosas de tipo autoinmune que se caracterizan por la producción de autoanticuerpos contra las proteínas del desmosoma tipo desmogleínas. Lo que diferencia el fenotipo de estas patologías es el nivel de la epidermis en el cual se localiza el antígeno involucrado. Presentamos un caso de una paciente con las características histológicas típicas de las dos enfermedades, identificadas en la misma biopsia de una lesión de la mucosa oral.

\section{Caso clínico}

Paciente femenina, de 56 años, con cuadro clínico de 20 días de evolución de placas alopécicas, erosionadas y húmedas, con escamas amarillas asociadas a caída de pelo con la tracción, localizadas en la región biparietal del cuero cabelludo (Figura 1). Presentaba además vesículas flácidas de contenido seroso y placas eritematosas, edematosas, algunas erosionadas con costras hemáticas, distribuidas en áreas seborreicas: región retroauricular, pecho y espalda (Figura 2), con signo de Nikolsky positivo. No refería antecedentes de importancia. Con diagnóstico clínico de pénfigo foliáceo (PF) se tomó una biopsia de una lesión del tronco que mostró vesículas intraepidérmicas acantolíticas suprabasales y algunas subcórneas, y en la dermis un escaso infiltrado linfocitario con polimorfonucleares y púrpura. (Figura 3). (Figura 4). La inmunofluorescencia directa para IgG, C3, IgM e IgA fue negativa.

Quince días después de la toma de la biopsia la paciente presentó placas eritematosas, erosionadas y con sangrado fácil en la mucosa yugal (Figura 5). Una biopsia de estas nuevas lesiones mostró acantólisis suprabasal, confirmándose el diagnóstico de pénfigo vulgar (PV) y una afección mucocutánea con características mixtas de PV y PF (Figura 6).

Se indicó tratamiento inmunomodulador con azatioprina $100 \mathrm{mg}$ al día y clobetasol 0,05\% en emulsión en las lesiones del cuero cabelludo y el resto de la piel, con mejoría clínica importante a los 20 días de iniciado dicho manejo.

\section{Discusión}

Este caso es interesante debido a la presentación inicial de lesiones en áreas seborreicas y con características clínicas de $\mathrm{PF}$, con posterior aparición de erosiones y ampollas en la mucosa oral, lo cual es característico de PV. La histología fue muy importante para definir el diagnóstico, ya que en un mismo campo se observaron vesículas con acantolísis suprabasal, típica del PV, coexistiendo con ampollas

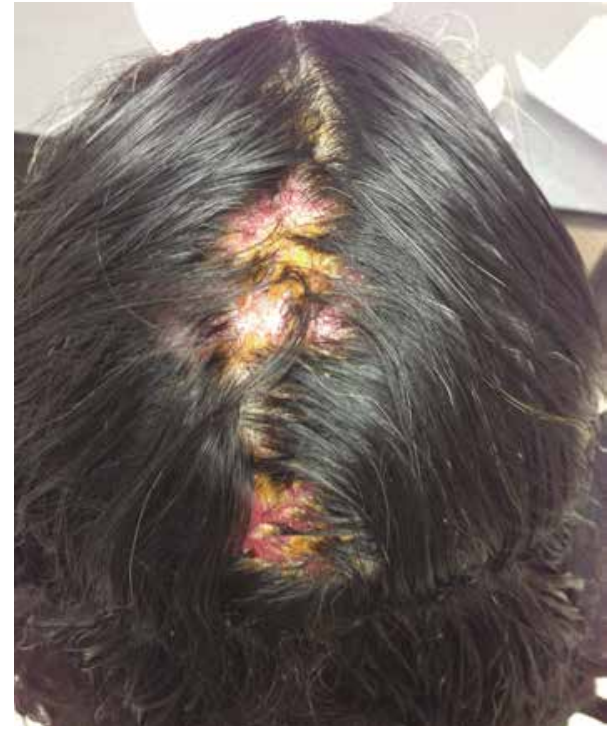

Figura 1. Placas eritematosas de superficie húmeda cubiertas por costras amarillas en el cuero cabelludo.

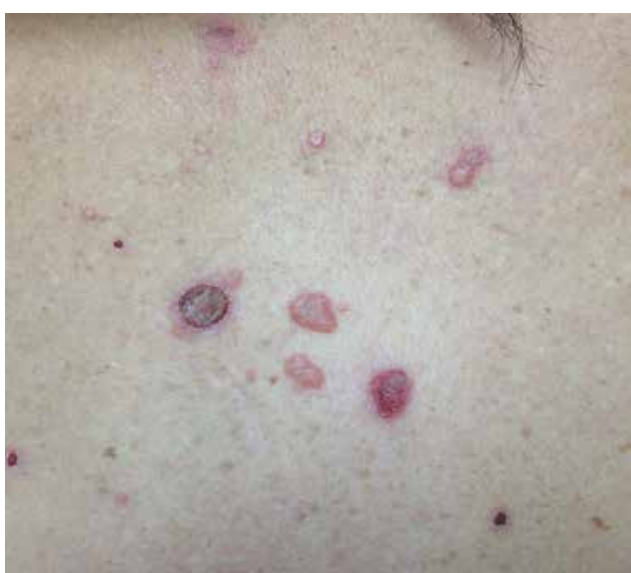

Figura 2. Vesículas flácidas de contenido claro y erosiones cubiertas por costras hemáticas localizadas en el dorso.

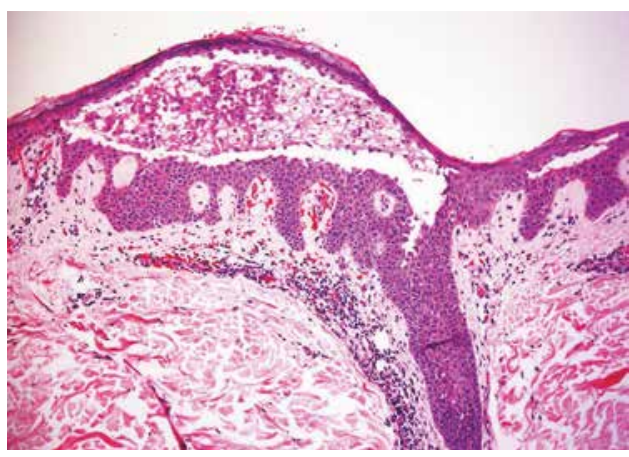

Figura 3. Biopsia de lesión del tronco. Acantolisis subcórnea con subsecuente formación de vesículas, hallazgo compatible con PF. Aumento 10X, Hematoxilina-Eosina 


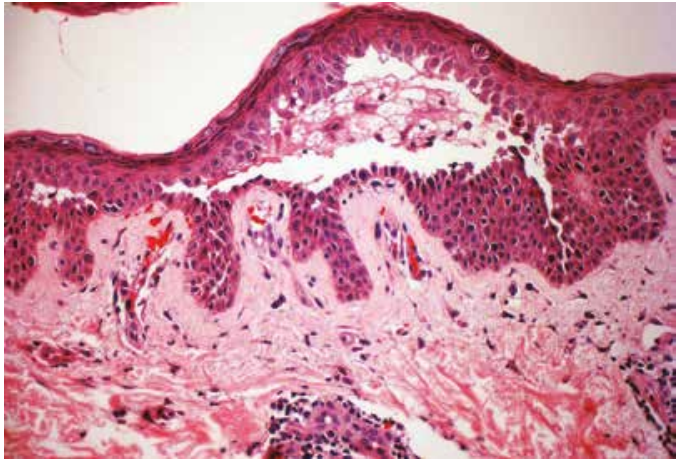

Figura 4. Biopsia de lesión del tronco. Acantolisis suprabasal con la clásica "fila de lápidas" descrita en el PV. Aumento de 10X, Hematoxilina-Eosina.

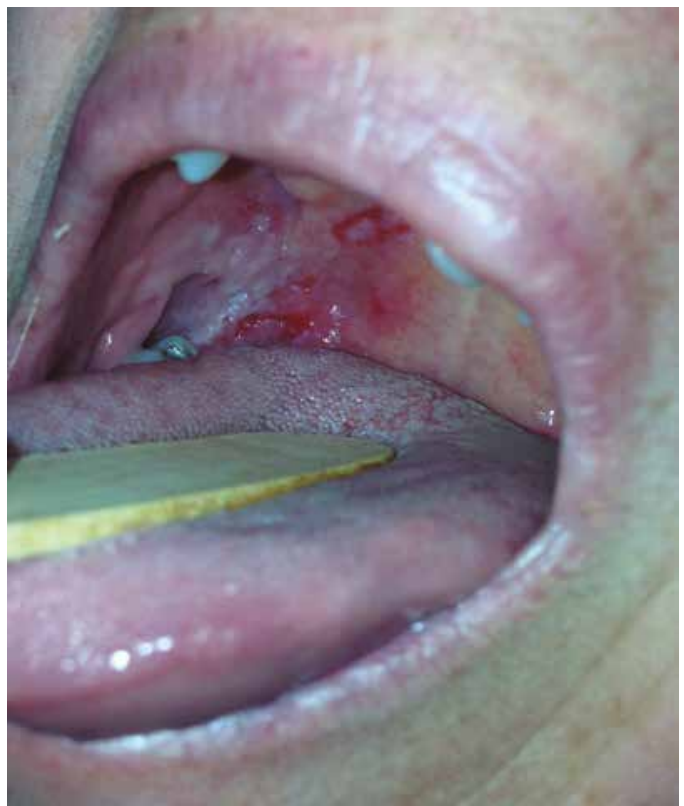

Figura 5. Mucosa oral con múltiples erosiones en el paladar blando subcórneas que se observan típicamente en el PF.

Los pénfigos son enfermedades autoinmunes que afectan la piel y las mucosas, caracterizadas por la formación de ampollas superficiales e intraepidérmicas debidas a la pérdida de adhesión intercelular. Son causadas por autoanticuerpos de tipo $\mathrm{G}\left(\mathrm{IgG}_{4}\right.$ dirigidos contra las proteínas desmosómicas de adhesión de la familia de las cadherinas, desmogleína 1 (Dsg-1) y desmogleína 3 (Dsg-3) (1).

Existen diferentes tipos de pénfigo, pero los más frecuentes son el PV y el PF. El cuadro clínico característico de estas dos variantes se diferencia principalmente por el nivel de la epidermis en el que se encuentra la acantolisis, siendo ésta suprabasal en el PV y subcórnea en el PF, lo cual se correlaciona con la distribución de las desmogleínas en la epidermis (2). La Dsg-3 se encuentra principalmente en la parte basal y suprabasal, y la Dsg-1 se expresa superficialmente con mayor intensidad, encontrándose poco en las mucosas (3). Estas proteínas se equilibran de tal forma que si se encuentran autoanticuerpos contra la Dsg3 en la piel, la Dsg-1 compensa la pérdida de su función manteniendo los queratinocitos unidos con formación de mínimas ampollas. Sin embargo, la Dsg-1 es muy escasa en las mucosas, por lo cual los anticuerpos contra la Dsg3 siempre causan vesículas en esta área, evidenciando la falta de compensación en tal localización (3).

Lo usual es que el pénfigo se manifieste con una sola de las formas clínicas, la correspondiente al perfil inmunológico del individuo que sufre la enfermedad. Sin embargo, en este caso ocurrió la superposición de las dos variantes en una misma localización, a diferencia de casos previamente reportados donde se han descrito las dos enfermedades en el mismo paciente pero en diferentes localizaciones (2, $4,5)$. Esta coexistencia se podría explicar por el hecho de que el suero de $\mathrm{PV}$ reacciona positivamente con antígenos

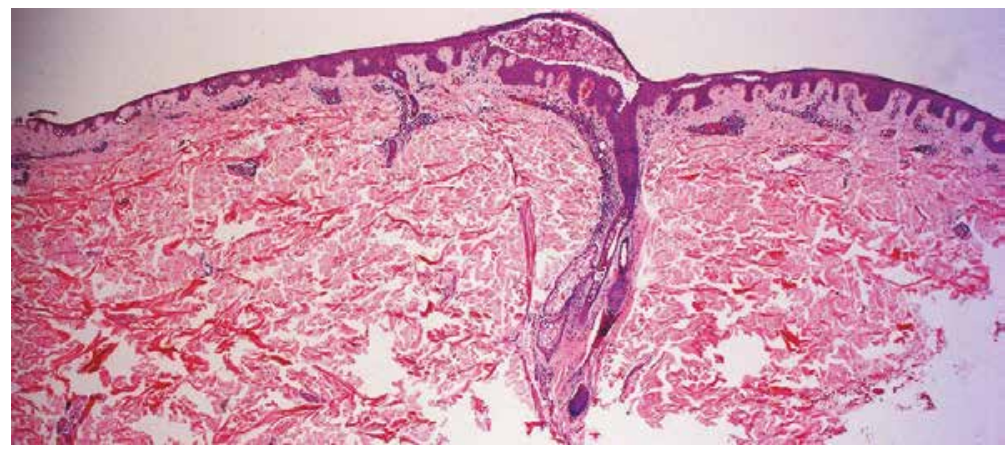

Figura 6. Biopsia de lesión del tronco. Se observan en un mismo campo vesículas con acantolisis suprabasal en el extremo izquierdo del campo y una vesícula con acantolisis subcórnea en el centro del mismo. Aumento 2.5X, Hematoxilina-Eosina 
de PF hasta en 64\% de los casos (4), sin embargo, llama la atención que la paciente que presentamos no tuvo inicialmente las lesiones en la mucosa oral características de PV hasta que en el estudio histopatológico se identificaron las ampollas suprabasales típicas de PV.

La inmunofluorescencia de ambos tipos de pénfigo se caracteriza por la presencia de depósitos de inmunoglobulina G, fracción del complemento C3, o ambos, en la superficie de los queratinocitos en un patrón reticular. Sin embargo, es importante anotar que este método no es positivo en todos los casos, por lo cual se han estudiado otras técnicas como el ensayo inmunoabsorbente ligado a enzimas, o ELISA por sus siglas en inglés, que podrían ser más sensibles y específicas para el diagnóstico de la enfermedad (6). Esta técnica permite evaluar la presencia de autoanticuerpos contra los dos tipos de desmogleínas, y tiene una sensibilidad de 90\% y especificidad de 95\%, lo cual implica un diagnóstico más preciso por medio de la misma (7).

En la literatura se encuentran algunos casos reportados de transición de una variante de pénfigo hacia otra, especialmente de PV a PF $(6,8)$. No obstante, en este caso el cuadro clínico fue agudo y no hubo un periodo de latencia entre la presentación de ambas manifestaciones. Se ha sugerido que el cambio fenotípico de las lesiones está relacionado directamente con una transición del perfil inmunológico, ocurriendo un viraje en la producción de autoanticuerpos contra Dsg-1 a Dsg-3 y visceversa, tal cambio se ha demostrado por ELISA y puede tener relación con el fenómeno de dispersión de epítopes (9). Así, con el daño inducido por los autoanticuerpos contra una de las desmogleínas se expondría la otra, que normalmente se encuentra "oculta" del sistema inmune, generando una sensibilización con producción de autoanticuerpos diferentes (8).

El tratamiento de los pénfigos incluye múltiples medicamentos inmunosupresores e inmunomoduladores como los glucocorticoides tópicos y sistémicos, la azatioprina, el mofetil micofenolato, la ciclosporina, la sulfasalazina, la pentoxifilina, la diamino-difenil sulfona, la inmunoglobulina humana intravenosa (IGIV) y la plasmaféresis (9). En algunos casos se ha usado rituximab, anticuerpo monoclonal anti CD20, con resultados favorables, especialmente cuando se inicia de forma temprana (10).

\section{Conclusión}

Reportamos el caso de una paciente con presentación simultánea de pénfigo foliáceo y pénfigo vulgar, una asociación de baja incidencia con pocos casos informados en la literatura, que pone de manifiesto las complejas interacciones inmunológicas que desencadenan la aparición de las lesiones ampollosas en esta enfermedad y cómo múltiples factores pueden estar involucrados en su desarrollo.

Agradecimientos: Agradecemos al Dr. Gerzaín Rodríguez por su invaluable colaboración con las fotografías histológicas y la revisión del manuscrito.

Conflicto de intereses: Ninguno reportado por los autores

Financiación: El desarrollo del artículo no contó con recursos de entidades nacionales ni internacionales.

\section{Referencias}

1. Amagai M. Adhesion molecules I: Keratinocyte-keratinocyte interactions; cadherins and pemphigus. $J$ Invest Dermatol. 1995; 104:146-52.

2. Feliciani C, Motta A, Castellaneta M, Federica M, De Benedetto $\mathrm{A}$, Toto $\mathrm{P}$, et al. Coexisting pemphigus vulgaris and pemphigus foliaceus in the same patient. Int J Dermatol. 2005;44:139-41.

3. Amagai M. Autoimmunity against desmosomal cadherines in pemphigus. J Dermatol Sci. 1999;92-102.

4. Izumi T, Seishima M, Satoh S, Ito A, Kamiya H, Kitajima Y. Pemphigus with features of both vulgaris and foliaceus variants, associated with antibodies to 160 and $130 \mathrm{kDa}$ antigens. $\mathrm{Br} J$ Dermatol. 1998;139:688-92.

5. Martel P, Cordel N, Courville P, Gilbert D, Musette P, Joly P. Pemphigus with clinical, histological and immunological features of both vulgaris and foliaceus subtypes. Br J Dermatol. 2002;147:1263.

6. Harman KE, Gratian MJ, Shirlaw PJ, Bhogal BS, Challacombe SJ, Black MM. The transition of pemphigus vulgaris into pemphigus foliaceus: a reflection of changing desmoglein 1 and 3 autoantibody levels in pemphigus vulgaris. Br J Dermatol. 2002;146:684-67.

7. Joly P, Litrowski N. Pemphigus group (vulgaris, vegetans, foliaceus, hepetiformis, brasiliensis). Clin Dermatol. 2011;29:432-6.

8. Kimoto M, Ohyama M, Hata Y, Amagai M, Nishikawa T. A case of pemphigus foliaceus which occurred after five years of remission from pemphigus vulgaris. Dermatology. 2001;203:174-6.

9. Komai A, Amagai M, Ishii K, Nishikawa T, Chorzelski T, Matsuo $\mathrm{I}$, et al. The clinical transition between pemphigus foliaceus and pemphigus vulgaris correlates well with the changes in autoantibody profile assessed by an enzyme-linked inmmunosorbent assay. $\mathrm{Br} J$ Dermatol. 2001;144:1177-82.

10. Lunardon L, Tsai KJ, Propert KJ, Fett N, Stanley JR, Werth VP, et al. Adjuvant rituximab therapy of pemphigus: a single-center experience with 31 patients. Arch Dermatol. 2012;148:1031-6. 